\title{
Preoperative factors predictive of postoperative decimal visual acuity $\geq 1.0$ following surgical treatment for idiopathic epiretinal membrane
}

This article was published in the following Dove Press journal:

Clinical Ophthalmology

3 February 2011

Number of times this article has been viewed

\author{
Hiroshi Kunikata' \\ Toshiaki Abe ${ }^{2}$ \\ Jiro Kinukawa' \\ Kohji Nishida ${ }^{1,3}$ \\ 'Department of Ophthalmology and \\ Visual Science, Tohoku University \\ Graduate School of Medicine, Sendai, \\ Japan; ${ }^{2}$ Division of Clinical Cell \\ Therapy, Tohoku University Graduate \\ School of Medicine, Sendai, Japan; \\ ${ }^{3}$ Department of Ophthalmology, \\ Osaka University Medical School, \\ Suita, Japan
}

Purpose: To report the preoperative best-corrected visual acuity (BCVA) and foveal thickness (FT) values that lead to a postoperative decimal BCVA of $\geq 1.0$ after surgical removal of an idiopathic epiretinal membrane (ERM).

Methods: This is a retrospective case series of 73 eyes that underwent surgery for removal of an idiopathic ERM. All eyes had been treated by a single surgeon using a 25-gauge transconjunctival sutureless vitrectomy and indocyanine green-assisted internal limiting membrane peel. The BCVA and FT were measured at baseline and 6 months postoperatively.

Results: A postoperative decimal $\mathrm{BCVA} \geq 1.0$ was obtained in eyes with a preoperative decimal $\mathrm{BCVA} \geq 0.3$ but not in those with a preoperative decimal BCVA $\leq 0.2$. The incidence of obtaining a postoperative decimal $\mathrm{BCVA} \geq 1.0$ was significantly $(P=0.002)$ higher in eyes with a preoperative decimal $\mathrm{BCVA} \geq 0.5(50 \%)$ than in eyes with a preoperative decimal $\mathrm{BCVA}<0.5$ (11\%). Additionally, a postoperative decimal BCVA of $\geq 1.0$ was obtained in $51 \%$ of the eyes that had a preoperative FT $<400 \mu \mathrm{m}$, compared with only $21 \%$ of eyes with a preoperative $\mathrm{FT} \geq 400 \mu \mathrm{m}(P=0.01)$. The incidence of obtaining a postoperative decimal BCVA $\geq 1.0$ was significantly higher in eyes with preoperative decimal BCVA $\geq 0.5$ and $\mathrm{FT}<400 \mu \mathrm{m}(60 \%)$ than in eyes with preoperative decimal BCVA $\geq 0.5$ and $\mathrm{FT} \geq 400 \mu \mathrm{m}(20 \% ; P=0.03)$ or preoperative $\mathrm{BCVA}<0.5$ and $\mathrm{FT} \geq 400 \mu \mathrm{m}(7 \% ; P<0.001)$.

Conclusions: These findings indicate that eyes with both preoperative BCVA $\geq 0.5$ and FT $<400 \mu \mathrm{m}$ have a significantly better chance of obtaining a postoperative decimal $\mathrm{BCVA} \geq 1.0$ following idiopathic ERM removal.

Keywords: 25-gauge vitrectomy, optical coherence tomography, epimacular membrane, epiretinal membrane, visual acuity, foveal thickness

\section{Introduction}

The surgical indications for the removal of an epiretinal membrane (ERM) have not been standardized. The removal of an ERM is helpful for many patients, but the surgical complications, such as endophthalmitis and retinal detachment, can negate the effectiveness of the removal. ${ }^{1-3}$ Because eyes with an idiopathic ERM have moderately good preoperative vision, the eyes to undergo surgery to remove an ERM should be carefully selected. The selection depends on the patient's symptoms and visual requirements, and the vitreous surgeon's technique. A postoperative decimal best-corrected visual acuity (BCVA) $\geq 1.0$ (BCVA Snellen chart $\geq 20 / 20$ ) is a positive result of removing an idiopathic ERM. ${ }^{4-7}$

A 25-gauge transconjunctival sutureless vitrectomy (25G-TSV) and membranectomy for the treatment of idiopathic ERM was first reported in 2002 by Fuji et al. ${ }^{8,9}$ This
Correspondence: Hiroshi Kunikata Department of Ophthalmology and Visua Science, Tohoku University Graduate School of Medicine, I-I Seiryo-machi, Aoba-ku, Sendai 980-8574, Japan

Tel +8I 227177294

Fax +81227177298

Email kunikata@oph.med.tohoku.ac.jp 
procedure has evolved and become more common over the years. The main advantage of this technique is that the intraoperative procedure is sutureless, meaning that the wounds are self-sealing. This reduces postoperative ocular pain and discomfort and procedure time, as well as the complications (eg, inflammation, astigmatism). In addition, using a 25G-TSV for the treatment of an idiopathic ERM leads to earlier postoperative visual improvement, compared with conventional 20-gauge vitrectomy. ${ }^{10,11}$ Because 25G-TSV retains the vitreous, the possibility of endophthalmitis has been discussed for many years, but a recent multicenter report of over 40,000 cases indicated no difference. ${ }^{12}$

Though there are many reports of postoperative favorable visual outcomes and visual improvements that may not be exactly defined as decimal BCVA $\geq 1.0$, we could not find any reports on preoperative findings that ensure a postoperative decimal BCVA $\geq 1.0$ in patients with ERMs. The purpose of this study was to determine the preoperative BCVA and foveal thickness (FT) in eyes with an idiopathic ERM that would help predict a postoperative $\mathrm{BCVA} \geq 1.0$ following $25 \mathrm{G}-\mathrm{TSV} / \mathrm{membranectomy}$.

\section{Patients and methods Participants}

This was a retrospective case series of 73 eyes of 73 patients with idiopathic ERMs who underwent 25G-TSV (Alcon Laboratories; Fort Worth, TX, USA)/membranectomy. The inclusion criterion was a clinically detectable idiopathic ERM diagnosed by fundus examination or optical coherence tomography (OCT), causing a decrease of visual acuity or metamorphopsia as reported by the patient; a questionnaire; or Amsler grid findings. The exclusion criteria included prior vitreous surgery, prior intravitreal injection of triamcinolone acetonide or antivascular endothelial growth factor, ocular inflammation, prior scleral buckling, prior trauma, and eyes with complex vitreoretinal disease such as proliferative vitreoretinopathy or proliferative diabetic retinopathy. None of the patients was excluded because of a decimal BCVA $<0.05$. The preoperative demographics of the patients are shown in Table 1.

All of the surgeries were performed at the Surgical Retina Clinic of the Tohoku University Hospital, Sendai, Japan, from July 2006 to November 2008. After the purpose and procedures of the operation were explained, an informed consent was obtained from all patients. The procedures used conformed to the tenets of the Declaration of Helsinki and were approved by the Review Board of the School of Medicine, Tohoku University.
Table I Summary of clinical data

\begin{tabular}{|c|c|c|}
\hline Characteristics & Value & $P$ value \\
\hline Eyes (no.) & 73 & \\
\hline Patients (no./\%) & 73 & \\
\hline Male & $24(33)$ & \\
\hline Female & $49(67)$ & \\
\hline \multicolumn{3}{|l|}{ Age (yrs) } \\
\hline Mean \pm SD & $67.2 \pm 10.4$ & \\
\hline Median & 68 & \\
\hline Range & $28-87$ & \\
\hline \multicolumn{3}{|c|}{ Lens status (baseline; no./\%) } \\
\hline Phakic & $61(84)$ & \\
\hline Pseudophakic & $12(16)$ & \\
\hline \multicolumn{3}{|c|}{ Surgical procedure (no./\%) } \\
\hline 25G-TSV & $34(47)$ & \\
\hline Triple surgery & $39(53)$ & \\
\hline \multicolumn{3}{|l|}{ Decimal BCVA (mean) } \\
\hline Baseline & 0.59 & \\
\hline Postoperative 6M & 0.74 & \\
\hline \multicolumn{3}{|c|}{ BCVA (logMAR; mean $\pm S D)$} \\
\hline Baseline & $0.23 \pm 0.25$ & \\
\hline Postoperative 6M & $0.13 \pm 0.27$ & $<0.00 I^{*}$ \\
\hline Improvement & $0.10 \pm 0.21$ & \\
\hline \multicolumn{3}{|c|}{ Foveal thickness $(\mu \mathrm{m}$; mean $(\mathrm{SD})$} \\
\hline Baseline & $371 \pm 106$ & \\
\hline Postoperative 6M & $300 \pm 67$ & $<0.00 I^{*}$ \\
\hline Reduction & $71 \pm 43$ & \\
\hline
\end{tabular}

Notes: *Wilcoxon signed-rank test, Postoperative 6M versus baseline. Triple surgery, phaceomulsification and aspiration, intraocularlens implant, and 25-gauge transconjunctival sutureless vitrectomy.

Abbreviations: SD, standard deviation; 25G-TSV, 25-gauge transconjunctival sutureless vitrectomy; BCVA, best-corrected visual acuity; logMAR, logarithm of the minimum angle of resolution.

\section{Surgical procedures}

All surgeries were performed under retrobulbar anesthesia by a single surgeon (HK). A conjunctival peritomy was not made in all cases, and all surgeries were performed with the 25G Accurus Vitrectomy System (Alcon Laboratories). Patients with concomitant lenticular changes had a combined sutureless 25G-TSV and phacoemulsification.

After resecting the vitreal core, about $4 \mathrm{mg}$ of triamcinolone acetonide (TA; Kenacort-A, Bristol-Myers Squibb, Tokyo, Japan) was injected into the vitreous cavity to determine whether a posterior vitreous detachment (PVD) was present. If a PVD was not present, we created a PVD with a 25-gauge cutter. After creating a PVD and removing residual gel, the epiretinal membrane was removed without using any dye. In addition, the internal limiting membrane (ILM) was removed using indocyanine green (ICG; Santen Co., Osaka, Japan) to improve visibility. The ICG crystals were reconstituted in $1.00 \mathrm{~mL}$ distilled water to produce a concentration of $25 \mathrm{mg} / \mathrm{mL}$. Further dilutions were made with 
$19 \mathrm{~mL}$ balanced salt solution. Thus, the final concentration of ICG was $1.25 \mathrm{mg} / \mathrm{mL}$, and approximately $0.2 \mathrm{~mL}$ of it was injected around the ERM.

Postoperatively, both antibiotics and corticosteroids were injected subconjunctivally in all cases. We used topical nonsteroidal anti-inflammatory drugs for all cases for at least 3 months after the membrane peel.

\section{Measurements of clinical findings}

All of the patients had a complete ophthalmological examination, including BCVA and FT measurements preoperatively and at 6 months postoperatively. The BCVA was determined with a standard Japanese Landolt visual acuity chart. FT was measured by OCT (Zeiss-Humphrey model OCT-3000, Dublin, CA, USA) before and after the 25G-TSV. The retinal thickness of the central fovea was defined as the distance between the ILM and the retinal pigment epithelium and was automatically calculated by the software of the OCT.

\section{Statistical analyses}

The data are presented as mean \pm standard deviation. The significance of the differences between the pre- and post-25G-TSV data was determined by Wilcoxon signed-rank tests. To obtain a postoperative decimal $\mathrm{BCVA} \geq 1.0$, the distribution of preoperative decimal BCVA and preoperative FT was assessed by Fisher's exact probability test. The decimal BCVA was converted to a logarithm of the minimal angle resolution (logMAR) units for statistical analyses. Spearman's rank correlation coefficient was calculated to determine the correlation between postoperative BCVA (logMAR) and preoperative BCVA (logMAR), and between postoperative BCVA $(\log$ MAR) and preoperative FT. A $P$ value $<0.05$ was considered to be statistically significant.

\section{Results}

A summary of the clinical data is shown in Table 1. The patients included 24 men and 49 women whose mean \pm standard deviation age was $67.2 \pm 10.4$ years. The mean postoperative follow-up period was $9.8 \pm 3.5$ months with a range of 6-21 months. The mean preoperative BCVA was 0.59 (decimal) or $0.23 \log$ MAR units. Phacoemulsification and aspiration, intraocular lens implantation, and 25G-TSV were performed on 39 eyes (53\%), and 25G-TSV only was performed on 34 eyes (47\%). In the 22 phakic eyes that had ERM surgery without cataract surgery, there was only one patient whose lens sclerosis progressed postoperatively, and cataract surgery was performed after 5 months from the initial
ERM surgery. None of the patients required suturing of the sclerotomy site at the end of the initial surgery.

The mean postoperative BCVA at 6 months was $0.13 \pm 0.27 \log$ MAR units, which was significantly better than the preoperative BCVA of $0.23 \pm 0.25 \log$ MAR units $(P<0.001$, Wilcoxon signed-rank test). The mean postoperative FT was $300 \pm 67 \mu \mathrm{m}$, which was significantly thinner than the preoperative FT of $371 \pm 106 \mu \mathrm{m}(P<0.001$, Wilcoxon signed-rank test).

A summary of the correlations between the BCVA and FT is shown in Table 2. The preoperative BCVA (in $\log$ MAR units) was significantly correlated to the preoperative FT ( $r=0.43, P<0.001$, Spearman's rank correlation coefficient). The postoperative BCVA was significantly correlated with the postoperative FT $(r=0.26, P=0.03$, Spearman's rank correlation coefficient). The preoperative BCVA was significantly correlated with the postoperative BCVA ( $r=0.44, P<0.001$, Spearman's rank correlation coefficient, Figure 1). The preoperative FT was also significantly correlated with the postoperative BCVA ( $r=0.24, P=0.04$, Spearman's rank correlation coefficient, Figure 2). The mean of the visual improvement (preoperative BCVA - postoperative BCVA in logMAR units) was 0.10 $\log$ MAR units, and this improvement was correlated with the preoperative BCVA ( $r=0.55, P<0.001$, Spearman's rank correlation coefficient). Thus, the postoperative visual improvement was greater in eyes with initially poorer preoperative vision. However, the postoperative visual improvement was not significantly correlated with the preoperative FT ( $r=0.21, P=0.07$, Spearman's rank correlation coefficient). The reduction of FT (preoperative FT - postoperative FT) was strongly correlated with the preoperative FT $(r=0.80, P<0.001$, Spearman's rank correlation coefficient). The reduction of FT was greater in

Table 2 Correlation between visual acuity and foveal thickness

\begin{tabular}{llll}
\hline & & r value & P value \\
\hline Reduction of FT & Preoperative FT & 0.80 & $<0.00 I^{*}$ \\
Visual improvement & Preoperative BCVA & 0.55 & $<0.00 I^{*}$ \\
Postoperative BCVA & Preoperative BCVA & 0.44 & $<0.00 I^{*}$ \\
Preoperative BCVA & Preoperative FT & 0.43 & $<0.00 I^{*}$ \\
Reduction of FT & Preoperative BCVA & $0.3 \mathrm{I}$ & $0.008^{*}$ \\
Postoperative BCVA & Postoperative FT & 0.26 & $0.03^{*}$ \\
Visual improvement & Reduction of FT & 0.24 & $0.04^{*}$ \\
Postoperative BCVA & Preoperative FT & 0.24 & $0.04^{*}$
\end{tabular}

Notes: *Spearman's correlation coefficient by rank. Reduction of FT, preoperative FT - postoperative FT; Visual improvement, preoperative BCVA - postoperative BCVA in logMAR units.

Abbreviations: FT, foveal thickness $(\mu \mathrm{m})$; BCVA, best-corrected visual acuity in logarithm of the minimum angle of resolution (logMAR). 


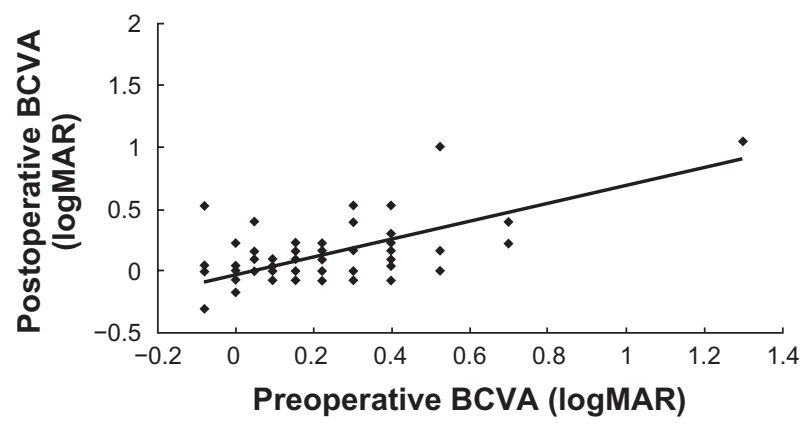

Figure I Coefficients of correlation between postoperative and preoperative BCVA. The postoperative BCVA at 6 months is significantly correlated with the preoperative BCVA ( $r=0.44, P<0.00$ I, Spearman's rank correlation coefficient). Abbreviations: BCVA, best-corrected visual acuity; logMAR, logarithm of the minimum angle of resolution.

eyes with thicker preoperative FT. The reduction of FT was also significantly correlated with the preoperative BCVA and postoperative visual improvement $(r=0.31, P=0.008$, and $r=0.24, P=0.04$, respectively, Spearman's rank correlation coefficient).

The associations between a preoperative decimal $\mathrm{BCVA}$ and a postoperative decimal $\mathrm{BCVA} \geq 1.0$ are shown in Table 3. A postoperative decimal $\mathrm{BCVA} \geq 1.0$ was obtained in 29 eyes with a preoperative decimal $\mathrm{BCVA} \geq 0.3$, but none of the eyes with a preoperative decimal $\mathrm{BCVA} \leq 0.2$ showed a postoperative decimal $\mathrm{BCVA} \geq 1.0$. The likelihood of obtaining a postoperative decimal $\mathrm{BCVA} \geq 1.0$ was $57 \%(12 / 21$ eyes $)$ in eyes with a preoperative decimal $\mathrm{BCVA} \geq 0.9,47 \%$ ( $7 / 15$ eyes) in eyes with preoperative decimal BCVA of $0.7-0.8,44 \%(8 / 18$ eyes) in eyes with preoperative decimal BCVA of $0.5-0.6$, and $13 \%(2 / 15$ eyes) in eyes with preoperative decimal BCVA of 0.3-0.4. The likelihood of obtaining a postoperative decimal $\mathrm{BCVA} \geq 1.0$ was significantly higher in eyes with a preoperative decimal $\mathrm{BCVA} \geq 0.9$ than preoperative

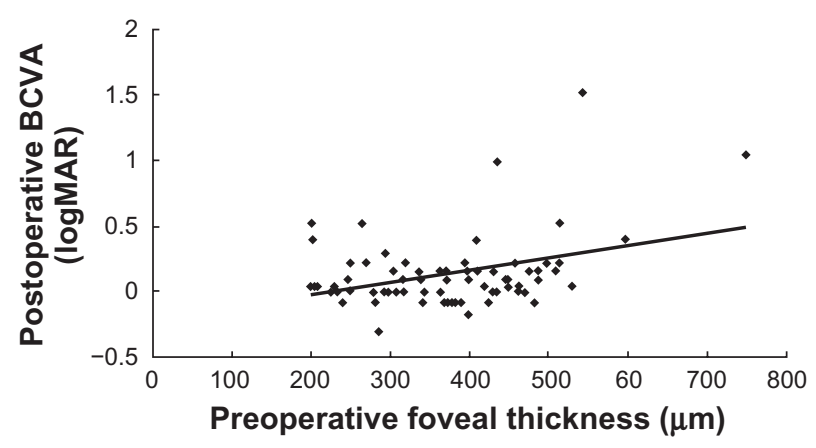

Figure 2 Coefficients of correlation between postoperative BCVA and preoperative foveal thickness. The postoperative BCVA at 6 months was significantly correlated with the preoperative foveal thickness $(r=0.24, P=0.04$, Spearman's rank correlation coefficient).

Abbreviations: BCVA, best-corrected visual acuity; logMAR, logarithm of the minimum angle of resolution.
Table 3 Association between preoperative decimal bestcorrected visual acuity and postoperative decimal best-corrected visual acuity $\geq 1.0$

\begin{tabular}{lll}
\hline $\begin{array}{l}\text { Preoperative } \\
\text { decimal BCVA }\end{array}$ & Eyes, no. & $\begin{array}{l}\text { Postoperative 6M decimal } \\
\text { BCVA } \geq \mathbf{I . 0 ,} \text { no (\%) }\end{array}$ \\
\hline$\geq 0.9$ & 21 & $12(57)$ \\
$0.7-0.8$ & 15 & $7(47)$ \\
$0.5-0.6$ & 18 & $8(44)$ \\
$0.3-0.4$ & 15 & $2(13)$ \\
$0.1-0.2$ & 2 & $0(0)$ \\
$\leq 0.09$ & 2 & $0(0)$ \\
Total & 73 & $29(40)$ \\
\hline
\end{tabular}

Notes: $P=0.002$, Fisher's exact probability test, $\geq 0.5$ versus $<0.5 ; P=0.008$, Fisher's exact probability test, $\geq 0.9$ versus $0.3-0.4 ; P=0.05$, Fisher's exact probability test, $0.7-0.8$ versus $0.3-0.4 ; P=0.06$, Fisher's exact probability test, $0.5-0.6$ versus $0.3-0.4 ; P=0.21$, Fisher's exact probability test, $\geq 0.9$ versus $0.5-0.6$; $P=0.39$, Fisher's exact probability test, $\geq 0.9$ versus $0.7-0.8 ; P=0.46$, Fisher's exact probability test, $0.7-0.8$ versus $0.5-0.6$.

Abbreviation: BCVA, best-corrected visual acuity.

decimal BCVA of $0.3-0.4(P=0.008$ Fisher's exact probability test). The likelihood of obtaining a postoperative decimal $B C V A \geq 1.0$ was significantly higher in eyes with a preoperative decimal $\mathrm{BCVA} \geq 0.5$ than preoperative decimal BCVA $<0.5(P=0.002$, Fisher's exact probability test $)$. In addition, there was no significant difference in the likelihood of obtaining a postoperative decimal BCVA $\geq 1.0$ between preoperative decimal BCVA $\geq 0.9$ and decimal BCVA of 0.7-0.8 and decimal BCVA of 0.5-0.6 (Table 3).

The associations between the preoperative FT and postoperative decimal BCVA $\geq 1.0$ are shown in Table 4 . The likelihood of obtaining a postoperative decimal BCVA $\geq 1.0$ was $21 \%(6 / 28$ eyes $)$ in eyes with a preoperative FT of $\geq 400 \mu \mathrm{m}, 56 \%$ (14/25 eyes) with a preoperative FT of 300 to $399 \mu \mathrm{m}, 47 \%$ (9/19 eyes) with a preoperative FT of $200-299 \mu \mathrm{m}$, and $0 \%(0 / 1$ eyes) in eyes with a preoperative FT of 100-199 $\mu \mathrm{m}$ (Table 4). The difference in the likelihood of obtaining a postoperative BCVA $\geq 1.0$ for preoperative FT of 300-399 $\mu \mathrm{m}$ and $200-299 \mu \mathrm{m}$ was

Table 4 Association between preoperative foveal thickness and postoperative decimal best-corrected visual acuity $\geq 1.0$

\begin{tabular}{lll}
\hline $\begin{array}{l}\text { Preoperative foveal } \\
\text { thickness }(\mu \mathrm{m})\end{array}$ & Eyes, no. & $\begin{array}{l}\text { Postoperative 6M decimal } \\
\text { BCVA } \geq \mathbf{I . 0}, \text { no }(\%)\end{array}$ \\
\hline$\geq 400$ & 28 & $6(21)$ \\
$300-399$ & 25 & $14(56)$ \\
$200-299$ & 19 & $9(47)$ \\
$100-199$ & 1 & $0(0)$ \\
Total & 73 & $29(40)$ \\
\hline
\end{tabular}

Notes: $P=0.01$, Fisher's exact probability test, $\geq 400 \mu \mathrm{m}$ versus $<400 \mu \mathrm{m} ; P=0.01$, Fisher's exact probability test, $\geq 400 \mu \mathrm{m}$ versus $300-399 \mu \mathrm{m} ; P=0.06$, Fisher's exact probability test, $\geq 400 \mu \mathrm{m}$ versus $200-299 \mu \mathrm{m} ; P=0.40$, Fisher's exact probability test, $300-399 \mu \mathrm{m}$ versus $200-299 \mu \mathrm{m}$.

Abbreviation: BCVA, best-corrected visual acuity. 
not significant $(P=0.40$, Fisher's exact probability test). In addition, the likelihood of obtaining a postoperative decimal $\mathrm{BCVA} \geq 1.0$ in eyes with a preoperative FT of $\geq 400 \mu \mathrm{m}$ was significantly lower in eyes with a preoperative FT of 300-399 $\mu \mathrm{m}(P=0.01$, Fisher's exact probability test). However, this relationship was not significant for preoperative FT of 200-299 $\mu \mathrm{m}(P=0.06$, Fisher's exact probability test). A postoperative decimal BCVA $\geq 1.0$ was obtained in $51 \%$ (23/45 eyes) of eyes with a preoperative FT $<400 \mu \mathrm{m}$, and the rate of obtaining a postoperative decimal $\mathrm{BCVA} \geq 1.0$ in eyes with a preoperative $\mathrm{FT}<400 \mu \mathrm{m}$ was significantly higher than that in eyes with an FT $\geq 400 \mu \mathrm{m}$ ( $P=0.01$, Fisher's exact probability test).

Association between preoperative findings and postoperative decimal BCVA $\geq 1.0$ are shown in Table 5. The incidence of obtaining a postoperative decimal $\mathrm{BCVA} \geq 1.0$ was significantly higher in eyes with preoperative decimal $\mathrm{BCVA} \geq 0.5$ and $\mathrm{FT}<400 \mu \mathrm{m}(60 \%)$ than in eyes with preoperative decimal BCVA $\geq 0.5$ and FT $\geq 400 \mu \mathrm{m}(20 \% ; \mathrm{P}=0.03$, Fisher's exact probability test) or preoperative $\mathrm{BCVA}<0.5$ and $\mathrm{FT} \geq$ $400 \mu \mathrm{m}(7 \% ; \mathrm{P}<0.001$, Fisher's exact probability test).

A summary of the clinical data of the eyes that had a postoperative decimal BCVA $\geq 1.0$ or $<1.0$ is shown in Table 6 . Statistical analyses on the eyes with a postoperative decimal $\mathrm{BCVA} \geq 1.0$ or decimal $\mathrm{BCVA}<1.0$ showed that the gender, age, lens status, and surgical procedures were not significantly different in the two groups. The mean preoperative BCVA and visual improvement were $0.13 \pm 0.15$ and $0.18 \pm 0.15 \log$ MAR units in the postoperative decimal BCVA $\geq 1.0$ group, whereas they were $0.30 \pm 0.29$ and $0.05 \pm 0.23 \log$ MAR units in the postoperative decimal BCVA $<1.0$ group $(P=0.004$ and $\mathrm{P}=0.01$, Mann-Whitney $U$ test). The mean preoperative FT was thinner in the postoperative decimal $\mathrm{BCVA} \geq 1.0$ group
( $P=0.07$, Mann-Whitney $U$ test $)$, but the difference was not significant, and the mean reduction of FT was significantly lower in the postoperative decimal BCVA $\geq 1.0$ group than in the postoperative decimal BCVA $<1.0$ group $(P<0.001$, Mann-Whitney $U$ test). The mean preoperative FT was $344 \pm 73 \mu \mathrm{m}$ in the postoperative decimal BCVA $\geq 1.0$ group, which was not significantly thinner than the $389 \pm 121 \mu \mathrm{m}$ in the postoperative decimal BCVA $<1.0$ group $(P=0.07$, Mann-Whitney $U$ test). However, the FT was reduced by $61 \pm 35 \mu \mathrm{m}$ in the postoperative decimal BCVA $\geq 1.0$ group, which was significantly less than the $77 \pm 48 \mu \mathrm{m}$ in the postoperative decimal BCVA $<1.0$ group $(P<0.001$, Mann-Whitney $U$ test).

\section{Discussion}

Our results showed that 25G-TSV and membranectomy used for the treatment of idiopathic ERMs were effective in significantly improving the BCVA and reducing the FT in patients with visual disturbances including decreased BCVA or metamorphopsia. In addition, we found that the postoperative BCVA was correlated with the preoperative BCVA, preoperative $\mathrm{FT}$, and postoperative FT. Approximately more than $50 \%$ of the eyes with a preoperative $\mathrm{BCVA} \geq 0.5$ and a preoperative $\mathrm{FT}<400 \mu \mathrm{m}$ attained a postoperative decimal BCVA $\geq 1.0$. Our results also demonstrated that the preoperative BCVA was significantly correlated not only with the postoperative BCVA but also with the improvement in the BCVA. Because the mean preoperative BCVA was significantly better in the postoperative decimal $\mathrm{BCVA} \geq 1.0$ group than in the postoperative decimal BCVA $<1.0$ group, a good preoperative BCVA was necessary to obtain a postoperative decimal $\mathrm{BCVA} \geq 1.0$, ie, a preoperative decimal BCVA

Table 5 Association between preoperative findings and postoperative decimal best-corrected visual acuity $\geq 1.0$

\begin{tabular}{llll}
\hline Group & Preoperative findings & Eyes, no. & $\begin{array}{l}\text { Postoperative 6M decimal } \\
\text { BCVA } \geq 1.0, \text { no (\%) }\end{array}$ \\
\hline 1 & Decimal BCVA $\geq 0.5$ and FT $<400$ & 40 & $24(60)$ \\
2 & Decimal BCVA $\geq 0.5$ and FT $\geq 400$ & 10 & $2(20)$ \\
3 & Decimal BCVA $<0.5$ and FT $<400$ & 8 & $2(25)$ \\
4 & Decimal BCVA $<0.5$ and FT $\geq 400$ & 15 & $1(7)$ \\
& Total & 73 & $29(40)$ \\
\hline
\end{tabular}

$P=0.03$, Fisher's exact probability test, Group I versus Group 2.

$P=0.08$, Fisher's exact probability test, Group I versus Group 3.

$P<0.00$ I, Fisher's exact probability test, Group I versus Group 4.

$P=0.62$, Fisher's exact probability test, Group 2 versus Group 3.

$P=0.35$, Fisher's exact probability test, Group 2 versus Group 4 .

$P=0.27$, Fisher's exact probability test, Group 3 versus Group 4 .

Abbreviations: $B C V A=$ best-corrected visual acuity; $\mathrm{FT}=$ foveal thickness $(\mu \mathrm{m})$. 
Table 6 Summary of clinical data by postoperative decimal best-corrected visual acuity $\geq 1.0$ or $<1.0$

\begin{tabular}{|c|c|c|c|}
\hline & $\begin{array}{l}\text { Postoperative } \\
\text { decimal BCVA } \geq 1.0\end{array}$ & $\begin{array}{l}\text { Postoperative } \\
\text { decimal BCVA }<1.0\end{array}$ & $P$ value \\
\hline No. eyes & 29 & 44 & \\
\hline No. patients & 29 & 44 & \\
\hline Gender (no./\%) & & & $0.08^{*}$ \\
\hline Male & $13(45)$ & II (25) & \\
\hline Female & $16(55)$ & $33(75)$ & \\
\hline \multicolumn{4}{|l|}{ Age (yrs) } \\
\hline Mean \pm SD & $65.9 \pm 12.8$ & $68.1 \pm 8.5$ & $0.57^{\#}$ \\
\hline Median & 68 & 67 & \\
\hline Range & $27-87$ & $50-82$ & \\
\hline Lens status (baseline; no./\%) & & & $0.69 *$ \\
\hline Phakic & $24(83)$ & $37(84)$ & \\
\hline Pseudophakic & $5(17)$ & $7(16)$ & \\
\hline Surgical procedure (no./\%) & & & $0.35^{*}$ \\
\hline 25G-TSV & $14(48)$ & $18(36)$ & \\
\hline Triple surgery & $15(52)$ & $26(64)$ & \\
\hline \multicolumn{4}{|l|}{ Decimal BCVA (mean) } \\
\hline Baseline & 0.74 & 0.50 & \\
\hline Postoperative 6M & 1.10 & 0.56 & \\
\hline \multicolumn{4}{|l|}{ BCVA (logMAR; mean $\pm S D)$} \\
\hline Baseline & $0.13 \pm 0.15$ & $0.30 \pm 0.29$ & $0.004^{\#}$ \\
\hline Postoperative $6 \mathrm{M}$ & $-0.04 \pm 0.07$ & $0.25 \pm 0.29$ & $<0.00 I^{\#}$ \\
\hline Improvement & $0.18 \pm 0.15$ & $0.05 \pm 0.23$ & $0.0 I^{\#}$ \\
\hline \multicolumn{4}{|c|}{ Foveal thickness $(\mu \mathrm{m}$; mean $\pm S D)$} \\
\hline Baseline & $344 \pm 73$ & $389 \pm 121$ & $0.07^{\#}$ \\
\hline Postoperative $6 \mathrm{M}$ & $283 \pm 39$ & $312 \pm 78$ & $0.1 \mathrm{I}^{\#}$ \\
\hline Reduction & $61 \pm 35$ & $77 \pm 48$ & $<0.00 \mathrm{I}^{\#}$ \\
\hline
\end{tabular}

Notes: *Fisher's exact probability test; \#Mann-Whitney test. Triple surgery, phacoemulsification and aspiration, intraocular lens implant, and 25-gauge transconjunctival sutureless vitrectomy.

Abbreviations: SD, standard deviation; 25G-TSV, 25-gauge transconjunctival sutureless vitrectomy; BCVA, best-corrected visual acuity; logMAR, logarithm of the minimum angle of resolution.

of $\geq 0.5$. Our findings indicated that the reduction of the FT was significantly lower in the postoperative decimal $\mathrm{BCVA} \geq 1.0$ group, which was also reasonable because the reduction of FT was significantly correlated with preoperative BCVA ( $\log M A R)$. On the other hand, although eyes with good preoperative BCVA showed a decreased likelihood of visual improvements, the improvement of the BCVA was significantly higher in the postoperative decimal $\mathrm{BCVA} \geq 1.0$ group than in the postoperative decimal $\mathrm{BCVA}<1.0$ group. The reason for this is unclear. However, the status of the photoreceptor inner and outer segment (IS/OS) or external limiting membrane (ELM) might be one of the explanations for this. The use of a spectral domain OCT would have helped in evaluating the photoreceptor integrity in more detail.

A postoperative decimal BCVA $\geq 1.0$ also correlated with a preoperative FT of $<400 \mu \mathrm{m}$. We suggest that because the preoperative FT was significantly correlated with the preoperative $\mathrm{BCVA}$ and the postoperative $\mathrm{BCVA}$, the postoperative $\mathrm{BCVA}$ was worse in eyes with thicker preoperative FT. If the preoperative FT was $\geq 400 \mu \mathrm{m}$, the preoperative decimal BCVA might be too low to attain a postoperative decimal $B C V A \geq 1.0$, even if the visual improvement was high. Thus, if the effects of the ERM had progressed to cause a lower decimal BCVA and thicker FT, the postoperative visual recovery of decimal BCVA $\geq 1.0$ would not be expected, in spite of a larger FT reduction and improvement in BCVA. We conclude that the eyes with both preoperative FT $<400 \mu \mathrm{m}$ and preoperative decimal $\mathrm{BCVA} \geq 0.5$ were the best candidates to obtain a postoperative decimal BCVA of $\geq 1.0$ postoperatively.

The improvement of the BCVA and reduction of the FT following surgery have been reported in the literature. ${ }^{713-16}$ Several studies have reported that the preoperative FT was significantly correlated with the preoperative BCVA, but the postoperative FT was not significantly correlated with the postoperative BCVA. ${ }^{15,17,18}$ However, a study by Suh et al reported that the postoperative FT was significantly correlated with the postoperative BCVA after ERM surgery, which is similar to our study. ${ }^{19}$ Discrepancies in the association of the postoperative BCVA and FT in earlier studies are probably 
due to different surgical procedures and low uniformity of various interventions, including ILM removal, dye used, and vitrectomy instruments (20 gauge or 25 gauge). If the ILM was completely removed as in the study by Shimada et al and this study, the residual ILM might not influence the postoperative macular surface to worsen the FT and BCVA. ${ }^{20}$

The removal of the ILM is still controversial because electrophysiological studies have shown some retinal dysfunction following ILM removal and because the use of dye had some retinal toxicity. ${ }^{21,22}$ However, studies have shown a decrease in the recurrences of ERM after ILM peeling and improvement of the BCVA and FT. ${ }^{20,23-25}$ Our results showed a $1.4 \%$ ( $1 / 73$ eyes) recurrence rate after more than a mean postoperative period of 9 months.

Because the IS/OS were not evaluated in the study presented, there have been two recent reports that discussed the association between the preoperative OCT images of the IS/OS junction of the photoreceptors and the visual outcomes after ERM surgery. ${ }^{17,19}$ We did not study the IS/OS junction as a prognostic factor because we were not able to precisely detect it because of the low resolution of the OCT we used. In addition, the IS/OS junction is difficult to detect when the FT is thick. Although it is more difficult to detect the ELM by low-resolution OCT, we believe that the BCVA in eyes with ERM would be correlated also with the status of ELM if it could be detected..$^{26,27}$ However, because our results showed that eyes with postoperative decimal $\mathrm{BCVA} \geq 1.0$ had good preoperative BCVA, and because the nonoperated ERM eyes with photoreceptor defects have significantly lower visual acuity, ${ }^{28}$ all of our cases that had a postoperative BCVA $\geq 1.0$ probably had a distinct IS/OS junction and ELM in the fovea. Thus, we believe that the preoperative BCVA and FT could be prognostic parameters for all ophthalmologists without knowing precisely the status of the IS/OS junction and even an ELM.

The duration of symptoms was not studied as a prognostic factor ${ }^{28,29}$ because the exact onset of the ERM, especially if the patients had good BCVA, is uncertain.

There are limitations of our study, including its retrospective nature, short follow-up period, small number of patients, and use of time-domain OCT. In addition, although a final decimal BCVA of 1.0 is only one aspect of the visual benefit in ERM surgery, and the degree of visual improvement and reduction of metamorphopsia are also important benefits of this surgery, the aim of this study was to identify factors that led to a postoperative decimal $\mathrm{BCVA} \geq 1.0$. Nevertheless, our findings indicate that surgery with
25G-TSV/membranectomy for idiopathic ERM is a useful method to obtain good decimal BCVA $\geq 1.0$ postoperatively. Based on our study results, a postoperative decimal BCVA of $\geq 1.0$ can be achieved in patients whose preoperative decimal BCVA has not deteriorated beyond 0.5 and whose central macular thickness has not exceeded $400 \mu \mathrm{m}$. However, many patients in this range of vision and FT are asymptomatic, and we should remember that all surgery carries inherent risks.

In conclusion, our findings indicate that eyes with both preoperative $\mathrm{BCVA} \geq 0.5$ and $\mathrm{FT}<400 \mu \mathrm{m}$ have a significantly better chance of obtaining a postoperative decimal $\mathrm{BCVA} \geq 1.0$ following removal of the idiopathic ERM.

\section{Note}

We thank Dr. Masahiko Shimura (Department of Ophthalmology, NTT East Japan Tohoku Hospital) for the critical comments on the manuscript. Parts of this paper were presented at the Annual Meeting of the Japanese Society of Clinical Ophthalmology, Fukuoka, Japan, in October 2009. This work was supported in part by research grants from the Ministry of Education, Culture, Sports, Science and Technology, Tokyo, Japan.

\section{Disclosure}

The authors report no conflicts of interest in this work.

\section{References}

1. Haas A, Seidel G, Steinbrugger I, et al. Twenty-three-gauge and 20-gauge vitrectomy in epiretinal membrane surgery. Retina. 2010;30: 112-116.

2. Rizzo S, Belting C, Genovesi-Ebert F, di Bartolo E. Incidence of retinal detachment after small-incision, sutureless pars plana vitrectomy compared with conventional 20-gauge vitrectomy in macular hole and epiretinal membrane surgery. Retina. 2010;30: 1065-1071.

3. Kunimoto DY, Kaiser RS. Incidence of endophthalmitis after 20- and 25-gauge vitrectomy. Ophthalmology. 2007;114:2133-2137.

4. Michels RG. Vitreous surgery for macular pucker. Am J Ophthalmol. 1981;92:628-639.

5. Michels RG. Vitrectomy for macular pucker. Ophthalmology. 1984;91: 1384-1388.

6. Hasegawa T, Emi K, Ikeda T, Watanabe M, Takaoka G. Long-term prognosis of internal limiting membrane peeling for idiopathic epiretinal membrane. Nippon Ganka Gakkai Zasshi. 2004;108: $150-156$.

7. Ishida M, Takeuchi S, Nakamura M, Morimoto K, Okisaka S. The surgical outcome of vitrectomy for idiopathic epiretinal membranes and foveal thickness before and after surgery. Nippon Ganka Gakkai Zasshi. 2004;108:18-22.

8. Fujii GY, de Juan E Jr, Humayun MS, et al. A new 25-gauge instrument system for transconjunctival sutureless vitrectomy surgery. Ophthalmology. 2002;109:1807-1812; discussion 1813.

9. Fujii GY, de Juan E Jr, Humayun MS, et al. Initial experience using the transconjunctival sutureless vitrectomy system for vitreoretinal surgery. Ophthalmology. 2002;109:1814-1820. 
10. Kadonosono K, Yamakawa T, Uchio E, Yanagi Y, Tamaki Y, Araie M. Comparison of visual function after epiretinal membrane removal by 20-gauge and 25-gauge vitrectomy. Am J Ophthalmol. 2006;142: 513-515.

11. Okamoto F, Okamoto C, Sakata N, et al. Changes in corneal topography after 25-gauge transconjunctival sutureless vitrectomy versus after 20-gauge standard vitrectomy. Ophthalmology. 2007;114: 2138-2141.

12. Oshima Y, Kadonosono K, Yamaji H, et al. Multicenter survey with a systematic overview of acute-onset endophthalmitis after transconjunctival microincision vitrectomy surgery. Am J Ophthalmol. 2010;150: 716-725.e1.

13. Niwa T, Terasaki H, Kondo M, Piao CH, Suzuki T, Miyake Y. Function and morphology of macula before and after removal of idiopathic epiretinal membrane. Invest Ophthalmol Vis Sci. 2003;44: $1652-1656$.

14. Lee JW, Kim IT. Outcomes of idiopathic macular epiretinal membrane removal with and without internal limiting membrane peeling: a comparative study. Jpn J Ophthalmol. 2010;54:129-134.

15. Koutsandrea CN, Apostolopoulos MN, Alonistiotis DA, et al. Indocyanine green-assisted epiretinal membrane peeling evaluated by optical coherence tomography and multifocal electroretinography. Clin Ophthalmol. 2007;1:535-544.

16. Hillenkamp J, Saikia P, Gora F, et al. Macular function and morphology after peeling of idiopathic epiretinal membrane with and without the assistance of indocyanine green. Br J Ophthalmol. 2005;89:437-443.

17. Mitamura Y, Hirano K, Baba T, Yamamoto S. Correlation of visual recovery with presence of photoreceptor inner/outer segment junction in optical coherence images after epiretinal membrane surgery. Br J Ophthalmol. 2009;93:171-175.

18. Massin P, Allouch C, Haouchine B, et al. Optical coherence tomography of idiopathic macular epiretinal membranes before and after surgery. Am J Ophthalmol. 2000;130:732-739.

19. Suh MH, Seo JM, Park KH, Yu HG. Associations between macular findings by optical coherence tomography and visual outcomes after epiretinal membrane removal. Am J Ophthalmol. 2009;147: 473-480.e3
20. Shimada H, Nakashizuka H, Hattori T, Mori R, Mizutani Y, Yuzawa M. Double staining with brilliant blue $\mathrm{G}$ and double peeling for epiretinal membranes. Ophthalmology. 2009;116:1370-1376.

21. Terasaki H, Miyake Y, Nomura R, et al. Focal macular ERGs in eyes after removal of macular ILM during macular hole surgery. Invest Ophthalmol Vis Sci. 2001;42:229-234.

22. Ueno S, Kondo M, Piao CH, Ikenoya K, Miyake Y, Terasaki H. Selective amplitude reduction of the PhNR after macular hole surgery: ganglion cell damage related to ICG-assisted ILM peeling and gas tamponade. Invest Ophthalmol Vis Sci. 2006;47: 3545-3549.

23. Kwok A, Lai TY, Yuen KS. Epiretinal membrane surgery with or without internal limiting membrane peeling. Clin Experiment Ophthalmol. 2005;33:379-385.

24. Kwok AK, Lai TY, Li WW, Woo DC, Chan NR. Indocyanine greenassisted internal limiting membrane removal in epiretinal membrane surgery: a clinical and histologic study. Am J Ophthalmol. 2004;138:194-199.

25. Park DW, Dugel PU, Garda J, et al. Macular pucker removal with and without internal limiting membrane peeling: pilot study. Ophthalmology. 2003;110:62-64.

26. Wakabayashi T, Fujiwara M, Sakaguchi H, Kusaka S, Oshima Y. Foveal microstructure and visual acuity in surgically closed macular holes: spectral-domain optical coherence tomographic analysis. Ophthalmology. 2010;117:1815-1824.

27. Wakabayashi T, Oshima Y, Fujimoto H, et al. Foveal microstructure and visual acuity after retinal detachment repair: imaging analysis by Fourier-domain optical coherence tomography. Ophthalmology. 2009; 116:519-528.

28. Michalewski J, Michalewska Z, Cisiecki S, Nawrocki J. Morphologically functional correlations of macular pathology connected with epiretinal membrane formation in spectral optical coherence tomography (SOCT). Graefes Arch Clin Exp Ophthalmol. 2007;245: 1623-1631.

29. Pesin SR, Olk RJ, Grand MG, et al. Vitrectomy for premacular fibroplasia. Prognostic factors, long-term follow-up, and time course of visual improvement. Ophthalmology. 1991;98:1109-1114.
Clinical Ophthalmology

\section{Publish your work in this journal}

Clinical Ophthalmology is an international, peer-reviewed journal covering all subspecialties within ophthalmology. Key topics include: Optometry; Visual science; Pharmacology and drug therapy in eye diseases; Basic Sciences; Primary and Secondary eye care; Patient Safety and Quality of Care Improvements. This journal is indexed on

\section{Dovepress}

PubMed Central and CAS, and is the official journal of The Society of Clinical Ophthalmology (SCO). The manuscript management system is completely online and includes a very quick and fair peer-review system, which is all easy to use. Visit http://www.dovepress.com/ testimonials.php to read real quotes from published authors. 